Paper ID \#18381

\title{
How Role-Playing Builds Empathy and Concern for Social Justice
}

\author{
Leslie Dodson, Worcester Polytechnic Institute \\ Dr. David DiBiasio, Worcester Polytechnic Institute
}

David DiBiasio is Associate Professor of Chemical Engineering and Department Head of ChE at WPI. He received his ChE degrees from Purdue University, worked for the DuPont Co, and has been at WPI since 1980. His current interests are in educational research: the process of student learning, international engineering education, and educational assessment. Collaboration with two colleagues resulted in being awarded the 2001 William Corcoran Award from Chemical Engineering Education. He served as 2004 chair of the ASEE ChE Division, has served as an ABET program evaluator and on the AIChE/ABET Education \& Accreditation Committee. He has also served as Assessment Coordinator in WPI's Interdisciplinary and Global Studies Division and as Director of WPI's Washington DC Project Center. He was secretary/treasurer of the new Education Division of AIChE. In 2009 he was awarded the rank of Fellow in the ASEE, and in 2013 was awarded the rank of Fellow in AIChE.

\section{Ms. Paula Quinn, Worcester Polytechnic Institute}

Through her role as Associate Director for the Center for Project-Based Learning at Worcester Polytechnic Institute, Paula Quinn works to improve student learning in higher education by supporting faculty and staff at WPI and at other institutions to advance work on project-based learning. She believes projectbased learning holds significant potential for increasing the diversity of students who succeed in college and who persist in science, technology, engineering, and math (STEM) fields, and she views her work with the Center as contributing to education reform from the inside out. She holds an M.A. in Developmental Psychology from Clark University and a B.A. in Psychology from Case Western Reserve University. Her background includes working in the field of education evaluation, where she focused primarily on the areas of project-based learning; STEM; pre-literacy and literacy; student life; learning communities; and professional development. She has worked on projects whose funding sources have included the National Science Foundation, the Institute of Education Sciences, and the U.S. Department of Education.

\section{Prof. John Bergendahl, Worcester Polytechnic Institute}

John Bergendahl is an Associate Professor in the Department of Civil and Environmental Engineering at Worcester Polytechnic Institute. He has six years experience as a practicing engineer in industry, and holds a B.S. in mechanical engineering, an M.S. in environmental engineering, and a Ph.D. in chemical engineering; all from the University of Connecticut. His recent research efforts are primarily directed at investigating novel treatment methods for emerging contaminants, and the development of systems and methods to sustainably treat water and wastewater.

\section{Kristin Boudreau, Worcester Polytechnic Institute}

Kristin Boudreau is Paris Fletcher Distinguished Professor of Humanities at Worcester Polytechnic Institute, where she also serves as Head of the Department of Humanities and Arts. Her training is in nineteenth-century literature, but for the past 8 years she has taught engineering ethics, first-year engineering courses, and humanities for engineers. She has also worked with students and colleagues to develop role-playing games teaching engineering within its complex humanistic context.

NOTE: this paper has co-authors.

\section{Glenn Gaudette, Worcester Polytechnic Institute}

Glenn R. Gaudette, $\mathrm{PhD}$, is a Professor of Biomedical Engineering at Worcester Polytechnic Institute. His research, which is supported by the National Institutes of Health and the National Science Foundation, aims to develop a treatment for the millions of Americans suffering from myocardial infarction and other cardiovascular diseases. In May of 2012, he co-founded a company based on some of the pioneering technology developed in his laboratory. Prof. Gaudette also teaches biomedical engineering design and innovation, biomechanics and physiology. He promotes the development of the entrepreneurial mindset in his students through support provided by the Kern Family Foundation. 


\section{Prof. John M. Sullivan Jr, Worcester Polytechnic Institute}

Professor John Sullivan joined WPI in 1987. He has had continuous external research funding from 1988 thru 2013. He has graduated (and supported) more than $75 \mathrm{MS}$ and PhD graduate students. He has served as the ME Department Head and in 2012 was elected Secretary of the Faculty through 2015. Prof. Sullivan has always maintained a full teaching load. He strongly supports the WPI project-based undergraduate philosophy.

Dr. Curtis Abel, Worcester Polytechnic Institute 


\title{
How Role-Playing Builds Empathy and Concern for Social Justice
}

\begin{abstract}
This paper describes an experimental first-year, two-term course designed by an interdisciplinary team of faculty from engineering, humanities, social science, and entrepreneurship and innovation. The first term of our course, "Humanitarian Engineering Past \& Present: Worcester, 1885," puts students in the roles of actual people living in a turn-of-the-century industrial city in central Massachusetts. While immersing themselves in the roles of engineers, industrialists, elected officials, workers, scientists, public health officials, inventors, and city residents, students learn and practice engineering concepts (engineering design, stakeholder analysis, mass balance, sewage treatment, material properties and selection, sewage properties and conveyance, statics and stress, filtration and chemical precipitation, and so on). These engineering concepts, though, are not abstracted from social, political, and economic considerations. Rather, engineering is imbued with social context. Through class events like town hall meetings, debates, and stakeholder analyses, students in character, are exposed to different perspectives, values, priorities, and constraints. Additional out-of-class work such as individual reflective essays and team-based projects also engaged them in ethical reasoning and complex cognitive tasks related to empathy, ethics, and social justice. In the follow-on course, students transitioned from their characters to address similar technical and social issues relevant to sanitation in the developing world. Looking forward to its third iteration, this course offers students opportunities to reflect on social justice and ethical issues while developing the qualities of compassion and empathy. This paper discusses our classroom activities and the ethical learning outcomes they produce. Course assessments employed a mixed-methods, triangulated approach that addressed several learning outcomes, including those related to ethics and social justice. Indirect instruments included standardized university course evaluations and a pre/post open prompt survey. Direct methods included student course work samples (a variety of written work, posters, presentations and final projects), a pre/post analysis of a scenario involving a hazardous chemical and a video-recorded session of teams analyzing an ambiguous scene indirectly related to course content.
\end{abstract}

\section{Background and Context}

"Humanitarian Engineering Past and Present" is an experimental first-year, two-term course designed and taught by an interdisciplinary team of faculty from engineering, humanities, and entrepreneurship and innovation at Worcester Polytechnic Institute (WPI), a technology-focused university in Worcester, Massachusetts. The university is best known for its 47 year-old project-based curriculum.

"Humanitarian Engineering Past and Present" provides a deep, integrative learning experience of benefit to both STEM and non-STEM students, and it is our hope that it will be used in liberal arts as well as technical institutions and courses. The course brings together content from both the humanities and engineering disciplines, and most classes and homework assignments are informed by transdisciplinary thinking. Our goal is to train a new generation of engineers who are well versed in the non-technical, human aspects of the engineering profession and who also have the technical skills to help improve society. Our primary means of pursuing our learning objectives is to assign each 
student a role to play for the duration of the first seven weeks and to ask that student to consider the challenges and course assignments through the lens of his or her particular character role in nineteenth-century Worcester at a time when the city and surrounding area were facing a large-scale waste-management problem. Through a wide range of classroom and team activities, students understand what life was like in the 1880s for people of a certain class, profession, ethnic group, and neighborhood.

\section{Relevance to Ethics}

Because a full cast of historical characters takes part in identifying and solving a sanitation problem, students are exposed to different perspectives, values, priorities, and constraints. Students learn to listen to one another, to consider different points of view, to compromise, and to identify and then rank design criteria. The engineering concepts they learn are not abstracted from social, political, and economic considerations. Rather, engineering concepts are imbued with context.

Students engage in ethical reasoning and experience complex cognitive tasks related to applied ethics. These include the tasks of determining the criteria that govern action and inaction, and considering their obligations to take or refrain from taking action in a specific situation.

Throughout the term, students develop and present their arguments in character, which often compels them to inhabit unfamiliar and uncomfortable perspectives. In role-play activities and assignments, they are called upon to weigh human, financial and engineering costs and benefits while navigating the ethical labyrinth that often accompanies large engineering projects. They must accept the tension of imperfect solutions and learn to make their way through the cognitive dissonance of conflicting points of view. As the course progresses, students become increasingly familiar with moral ambiguity, imperfect solutions and decisions with consequences.

\section{The Engineer of 2020}

This course supports the development of the "Engineer of 2020." Among the essential attributes for today's engineer, the National Academy of Engineering has identified the following: strong analytical skills, practical ingenuity, creativity, communication, an understanding of business and management, the principles of leadership, an ability to practice high ethical standards and professionalism, and the ability to adapt quickly to a changing world, including dynamism, agility, resilience, flexibility, and the capacity to be lifelong learners (National Academies, 2004). Many of these attributes are not expected outcomes of a traditional engineering curriculum, but instead must be pursued by means of curricular innovations, including transdisciplinary efforts like the one we describe here.

\section{Introduction and Statement of the Problem}

The Blackstone Canal was initially constructed to transport goods and people between landlocked Worcester and the seaport at Providence, Rhode Island. That purpose was quickly supplanted by rail lines, and by the end of the nineteenth century, the canal served as an open sewer and drainage mechanism for human and industrial waste. At that time, the city's industrial effluent and domestic wastes were deposited in the open canal, 
which traversed the city before emptying into the Blackstone River. The canal coursed through the low-lying areas of the city, flowing past predominantly immigrant neighborhoods populated by laborers and their families. Wealthy industrialists lived upslope and upstream, out of persistent exposure to the stench, filth and disease associated with sewage and industrial waste.

By the late 1800s, the dumping of industrial and domestic waste into the open canal had reached a critical juncture. Civil dissatisfaction brought about by the exacerbation of filth, foul smells, and disease, as well as disruptions to downstream industries, motivated the search for an engineered solution to the problem of openly discharged waste.

While inhabiting their roles of engineers, industrialists, elected officials, workers, scientists, public health officials, inventors, and city residents, students learn and practice engineering and considerations of social order and justice as they relate to the waste and sanitation crisis in Worcester at the end of the nineteenth century. Throughout the course, students are introduced to concepts such as engineering design, sewage properties and conveyance, sewage treatment, mass balance, material properties and selection, statics and stress, filtration and chemical precipitation. They simultaneously pursue an understanding of the social, economic, cultural and political contexts in Worcester at that time. This transdisciplinary course thus grounds the sanitation issues of a particular time and place within a broader set of circumstances that inform engineering decisions.

Through role-play activities, assignments and teamwork across a range of technical and social topics, students gain both an appreciation of the history of industrialization and technological advancement, and the competence to understand the science and technology within this history. Students learn about and practice the engineering design process; they learn wastewater characteristics and treatment methods in labs; they grapple with policy issues in a role-play debate; they familiarize themselves with professional codes of ethics; they reflect on the effects of race, class and privilege; they deconstruct power and influence through stakeholder analyses and absorb information on filtration, separation, chemical precipitation and other forms of treatment, and the consequences of ultimate waste disposal. The role-playing activities, which run intermittently throughout the first half of the semester, enable students to experience this course content from the particular vantage point and subject position of the role they are assigned.

\section{Sampling and Participants}

WPI's calendar is organized into four seven-week terms; "Humanitarian Engineering Past and Present" ran as an experimental two-term class (Spring 2016 and Fall 2016) for which first-year students received both a humanities credit and an elective engineering credit. The course offers students opportunities to reflect on social justice and ethical issues while developing the qualities of compassion and empathy. Below, we discuss the learning outcomes from the first term when students concentrated on inhabiting character roles set in the historical context of an industrial New England city in the late nineteenth century.

Our sample consists of 19 first-year students, all but one of them engineering majors. In the first offering, we had two white students, one male and one female. In the second 
offering, we had six female and 11 male students, including six students of color. Four of the six female students in the class were students of color. The course enrollment limit was 40 , but because enrollment in both courses was required for enrollment in either one, fewer students enrolled than we had hoped. The authors are aware of the limitations of the small sample size, but consider their findings and assessment of empathy, ethics and social justice learning outcomes to be sufficiently noteworthy to warrant sharing with the engineering education community.

\section{Data Collection Methods}

We used an online learning management system (Canvas) to collect individual and team assignments and student reflection essays, which we assessed for direct learning outcomes. End-of-term team posters provided data on integrative learning. Where relevant, we used faculty notes from in-class discussions and activities to assess the course and student learning, as well as numerous evaluation methods, which we describe in the Assessment section.

\section{Approach}

Students engaged in a variety of traditional and non-traditional coursework and assignments designed to generate an understanding of what life was like in the industrializing northeast around the turn of the nineteenth century. Students learned to "address complex social problems with creativity, cross-cultural communication skills, and an appreciation for diverse viewpoints" (Boudreau et al., 2016, p.9), while inhabiting the roles of people from a range of socio-economic classes, professions, religions, ethnic groups and neighborhoods. Below, in Table 1, we summarize five sets of assignments and activities that teach "engineering content in a complex social environment where ethical questions are part of engineering practice" (ibid.).

Table 1. Summary of sample modules used in "Humanitarian Engineering Past and Present."

\begin{tabular}{|c|}
\hline $\begin{array}{l}\text { Ethics and Social Justice through Role-play } \\
\text { Module: Role-play Debate. A Question of Policy } \\
\qquad \text { In-class, in-character debate } \\
\cdot \quad \text { Reflect on role-play }\end{array}$ \\
\hline $\begin{array}{l}\text { Science in the Service of Society and Science as Subject to Society } \\
\text { Module: Fluid Flow and Filtration Labs } \\
\qquad \text { Sewage transport and treatment } \\
\text { - Theories of disease transmission } \\
\text { - Human contexts around technical solutions }\end{array}$ \\
\hline $\begin{array}{c}\text { Ethics \& Cultures of Professionalism } \\
\text { Module: The Professionalization of Engineering } \\
\qquad \quad \text { Codes of ethics }\end{array}$ \\
\hline $\begin{array}{l}\text { Multiculturalism, Privilege and Empathy } \\
\text { Module: Reflection Essays }\end{array}$ \\
\hline $\begin{array}{l}\text { Sites of Industry, Culture, and Social Unrest } \\
\text { Module: Walking Tours }\end{array}$ \\
\hline
\end{tabular}




\section{Ethics and Social Justice through Role-play}

Module: Role-play Debate. A Question of Policy

The goal of the "Role-play Debate. A Question of Policy" assignment and activity is to familiarize students with a range of public-and private-sector perspectives that inform, and ultimately influence, engineering solutions. For this module, students were instructed to focus on issues of public policy only (i.e., should the city take some kind of action?) rather than any specific technical measures that could be implemented.

The class was split into two teams, with each team assigned to read opposing selections from The Sewage of Worcester in its Relation to the Blackstone River: Hearings Before the Joint Standing Committee on Public Health, on the Matter of Restraining the City of Worcester from Polluting the Blackstone River (1882). This document contains resident and witness statements and legal arguments by a) municipal representatives and others who argued against taking action to purify the water that empties into the Blackstone River and Canal, and, b) agents in favor of taking action (i.e., downstream industrialists and residents, doctors, social activists, laborers, etc.).

In-class, in-character debate:

Students were instructed to take a position on the question: "Should Worcester have to clean up the water it puts into the Blackstone River?" In an in-class debate, students represented their characters' primary interests and motivations and revealed their characters' conflicting interests (public and private, for example, or personal and professional).

Reflecting on role-play debate:

Following the role-playing debate, students posted a short reflection essay on their character's opinion and comments on the policy issues raised by the reading and the debate. Students found that the role-play debate helped them contextualize the readings, labs and lectures. Importantly, their responses displayed a heightened appreciation of technical and social tensions as they related to issues of ethics and social justice.

As an engineer I am with the people to demand change to our sewers. However as a city official I have to think about how we will pay for it, who will build it, how will it affect life in the city.

(Student response)

A(s a) resident for Worcester and a part owner for Atlanta Mill in Millbury, Mr. Harrington (has) concerns about Worcester's current sewage system for both moral and economic reasons.

(Student response)

I, Robert C. Booth, resident and owner of a medical practice in Millbury, found it hard to convince some people of the issue with dumping untreated sewage into the Blackstone River. Whether they are too concerned with their own businesses, time, or money, they don't seem to care that their ignorance is leading to the deaths of innocent children. 


\section{Science in the Service of Society and Science as Subject to Society}

Module: Fluid Flow and Filtration Labs

We blended science and social issues in lab activities to help students appreciate the role of science in informing policy and improving public health (Figures 1 and 2). In this case, as Worcester citizens became increasingly concerned about sewage flow and associated waterborne illnesses - and began to link those concerns with drinking water sourced from the canal - the ability to collect data, understand engineering challenges, and quantify pollutants in wastewater became a powerful tool for those advocating for a new sewage system.

Sewage transport and treatment:

Three major technical issues related to late nineteenth century wastewater processing were: gravity transport of sewage from places of generation to a treatment facility, characterizing the sewage content, and treating it before discharge into the Blackstone River. Students addressed these challenges in lab activities designed to teach fundamental engineering science with materials and equipment consistent with those available in the late nineteenth century. For example, as shown in Figure 1, students investigated variables such as viscosity, pipe diameter, pipe length, and hydrostatic pressure head during lab classes.

Figure 1. Students investigating gravity flow of simulated wastewater.

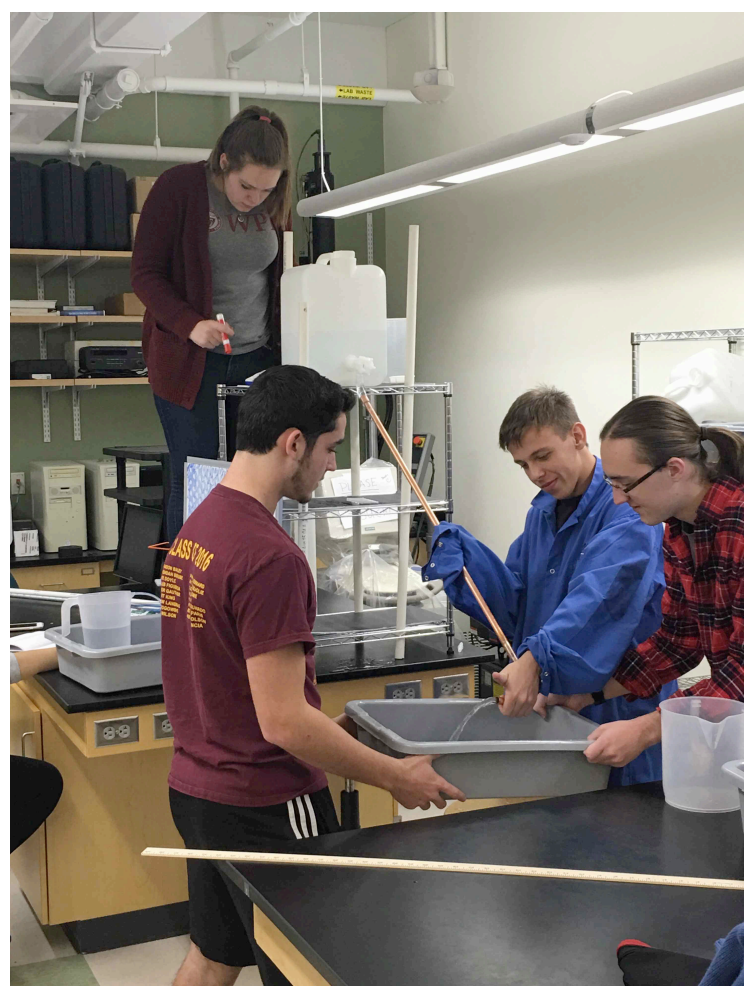

Characterizing wastewater:

One faculty member from civil engineering conducted a lab introducing students to 
wastewater samples from the area wastewater treatment facility, along with basic methods to characterize the wastewater. We discussed the approaches to characterizing this water that were available at the time (e.g. describing color, visual turbidity, solids). Then, using the Imhoff Cone, students measured organic content, turbidity, suspended solids, and readily settleable solids. They recorded $\mathrm{pH}$ readings of the wastewater before and after adding acid, simulating the discharge released into the canal from tannery and metalwork industries during the nineteenth century.

\section{Removing suspended solids:}

In a follow-on filtration lab, students simulated nineteenth-century devices and materials to study basic solids filtration (see Figure 2). A chemical engineering faculty member "gamified" a filtration lab, challenging teams to create the most effective filter to remove suspended solids (coffee grounds) from a solution. Using different media, teams

replicated a commonly used method for water and wastewater treatment. While learning about different operating variables that affect the filtration process, students also learned about historical water filtration systems and best practices of the time.

Figure 2. Students learn about different operating variables that affect the filtration process using simulated sewage and materials consistent with those available in the late nineteenth century.

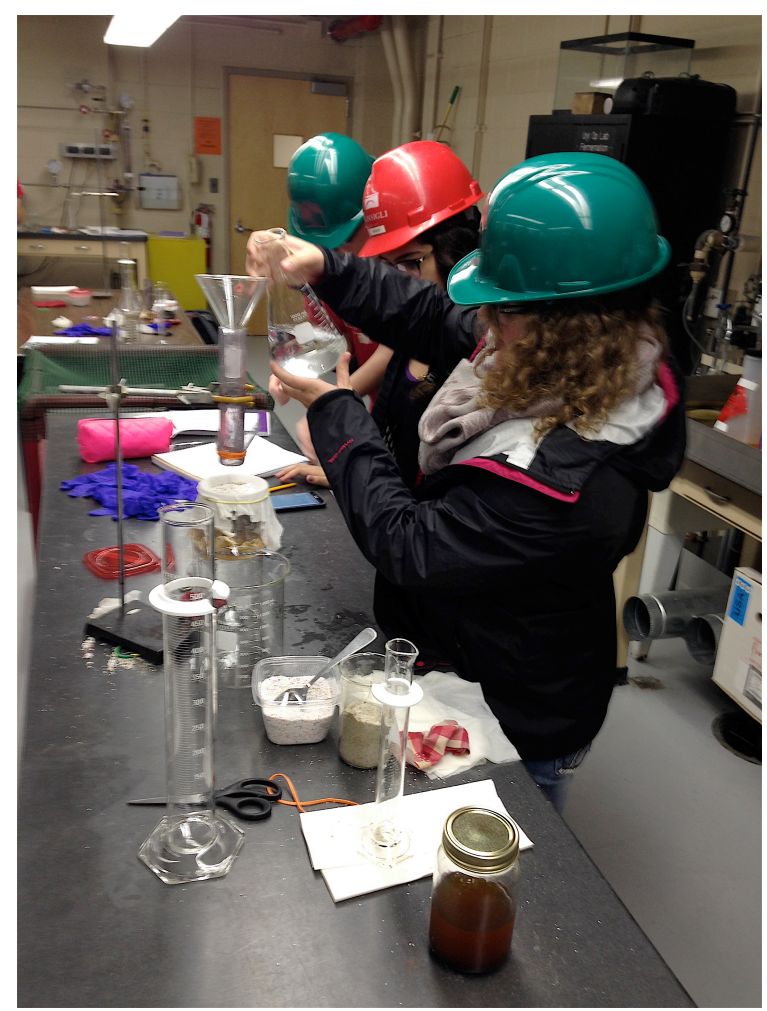

Theories of disease transmission:

In the mid-to-late nineteenth century, attention was turning away from the "miasma theory" of illness (which held that noxious air and odors caused illness) to "germ theory" 
(maintaining that bacteria, viruses and microorganisms caused diseases). However, while chemists and biologists adopted the germ theory of disease transmission, engineers were slower to be convinced, and our character roles capture this transitional state of scientific progress in the nineteenth century, with professionally educated engineers much more likely to side with public health officials, while self-trained engineers were more likely to hold to the miasma theory. The state of scientific and technical knowledge at that time complicated the ethical conversations among the medical, industrial and political establishments about the need for a new sanitation system. Through labs, readings, and role-play activities, students in "Humanitarian Engineering Past and Present" gained a deeper understanding not only of how science serves society, but also of how science is itself subject to cultural norms and prejudices. Thus, while our activities enabled students to better understand how potential solutions could mitigate contaminants and protect the general population from waterborne pathogens, they also developed a strong appreciation for the human contexts that complicate purely scientific and technical solutions.

\section{Ethics \& Cultures of Professionalism}

Module: The Professionalization of Engineering

As new evidence-based knowledge was used to help make the case for an updated sewage system, the engineering trade was simultaneously undergoing a transformation toward greater professionalism. In the 1850 s, engineers were often no more than skilled tradesmen, technicians or experienced builders and designers. Engineering only gained recognition as a separate occupation toward the end of the nineteenth century. The historical period captured by our role-playing games saw conflict within the profession, which had only recently been acknowledged as an occupation warranting specialized training or a codification of principles and best practices.

Codes of ethics:

We designed a course module to capture this transition in the culture of professionalism. Through readings, including "A Proposed Code of Ethics for All Engineers" (Christie, 1922) and in-class discussions, students considered why some engineers might want a code of ethics; why others might oppose a formal code of ethics; and what interests fall outside the first codes of ethics for engineering. The learning goal for this module was to prompt an appreciation for ethical codes not only as instruments that could help engineers navigate across competing viewpoints and provide guidance when solutions are not clearcut, but also as cultural artifacts used to wield and consolidate authority.

Through readings and discussion, students developed an appreciation of the ethics of engineering (i.e., to uphold safety, serve the public interest, perform within the bounds of their competence) in the midst of competing social, political and financial agendas. They were challenged to reconcile often-contradictory stances and ethical dilemmas presented by Worcester's sanitation problems. Furthermore, they wrestled with conflicting and competing agendas of financial cost-benefit analyses, political expediency, legal requirements and the alleviation of human suffering.

\section{Multiculturalism, Privilege and Empathy}

Module: Reflection Essays

In an effort to stimulate a consideration of the ways in which privilege, identity, and 
difference in the areas of race, gender, class, sexual orientation, and nationality operate in their own lives as well as within the broader context of "Humanitarian Engineering Past \& Present," students investigated their personal experiences of privilege and disadvantage and related these to circumstances in and around Worcester in the 1880s.

Student reflection essays incorporated readings from historians of immigrant and working-class culture from this period. Roy Rosenzweig's history of industrial workingclass culture in Worcester includes an ethnic profile of the city (Rosenzweig, 1983). Other readings traced the immigrant experience of two different populations. "Irish Emigration to the United States. What has been, what it is" (Byrne, 1873) describes the Irish Catholic working-class experience in the rapidly industrializing northeast, highlighting the prospects, duties, dangers, and mistakes of Irish emigrants to the U.S. In contrast, "A Swedish Working-Class Church-The Methodists of Quinsigamond Village (Estu, 1989) describes the largely stable, insular Swedish settlements located near the open sewer and early sewerage works. Estu describes the path of upward mobility of initially unskilled, industrial laborers employed in the burgeoning steel and wire industries in the late nineteenth century, highlighting the role of the Methodist Church in community building.

In their written essays, students reflected on how one or more of their own identities or privileges affected their awareness of social justice issues raised in the class. Choosing an identity group, they investigated how race, gender, class, nationality, or other aspects of identity explored in these readings shaped access to, or experience in, the industrializing city.

Excerpts revealed that students fused their contemporary self-knowledge with an empathetic understanding of the past.

I am a person born with multiple ethnicities. I am Puerto Rican, Dominican, English, Scottish, and Irish. I was surprised to discover how oppressed my Irish brethren were in Worcester during the 1800s. I always thought that my Hispanic side was the only sufferers of oppression, but my mind is a little more open now.

(Student response)

Being a female from a Latino background, I recognize that I will not carry throughout my life the privilege that comes with being a white, heterosexual, cisgender male.... The same issues that may be presented to me as a minority are some of the same issues the many of the different ethnic groups within 19th century Worcester faced.

(Student response)

I have been able to see the correlation between the past and present as I have noticed how those who were native-born...tended to be granted greater privilege through opportunity and success in nineteenth century Worcester.

(Student response) 
I realize our society today is still dealing with similar or even (the) same challenges on justice, for example, prejudice against women.

(Student response)

\section{Sites of Industry, Culture, and Social Unrest}

In addition to helping students make an empathetic connection between their own lived experiences and those of figures from the past, we also assigned physical activities connecting Worcester's past with students' present environment.

Module: Walking Tours

Via walking tours designed by the local historic preservation society ("By the Canal: Canal District Walking Tour," and "Around the Common: A Downtown Walking Tour"), students familiarized themselves with historic Worcester where churches, triple-decker workers' houses, and other industrial and cultural landmarks testify to the city's important role as an industrial economy at the end of the nineteenth century. We also prompted students to consider the numerous on-campus and nearby downtown buildings as reminders of the city's social, cultural and industrial past.

Students explored the city on foot and posted "selfies" from various locations along the tours. They examined Victorian-era mills where men and women toiled in the wire, tool, shoe and corset industries. They examined the public commons where, in our game, activists and residents clamored for health and sanitation improvements. They witnessed traces of immigrant cultures in the neighborhoods that had hosted waves of Irish, Italian, Polish, Lithuanian and other immigrants who came to build the canal and railroads and stayed to labor in industry. They discovered the site where the anarchist Emma Goldman, a radical agitator, union organizer and women's rights activist, briefly operated an ice cream shop.

By physically experiencing their environs, students were able to locate themselves in the otherwise abstract temporal and geographical context that shaped the sewage management problem we explore in the course. Extant structures and infrastructure enabled students to imagine the past and connect it to the present, giving them an appreciation of how the built landscape reflected, and continues to reflect, social, cultural and industrial priorities.

\section{Assessment}

We employed a mixed-methods, triangulated approach to assessing the course and student learning outcomes (Table 2). We secured IRB approval for all of our assessment activities. Indirect instruments included standardized university course evaluations and a pre/post open prompt survey. Direct methods included student course work samples (a variety of written work, posters, presentations and final projects), a pre/post analysis of a scenario involving a hazardous chemical scenario and a video-recorded session of teams analyzing an ambiguous scenario indirectly related to course content. Several of these instruments were used more than once in the two course offerings and there is an extensive collection of student artifacts. We recently completed transcripts of video 
sessions of five teams. Hence, we have collected a large volume of qualitative and quantitative data that we are just beginning to analyze. What follows is a preliminary sample of the most relevant data, which provides some early, emerging trends.

Table 2. Summary of various methods used to assess "Humanitarian Engineering Past and Present."

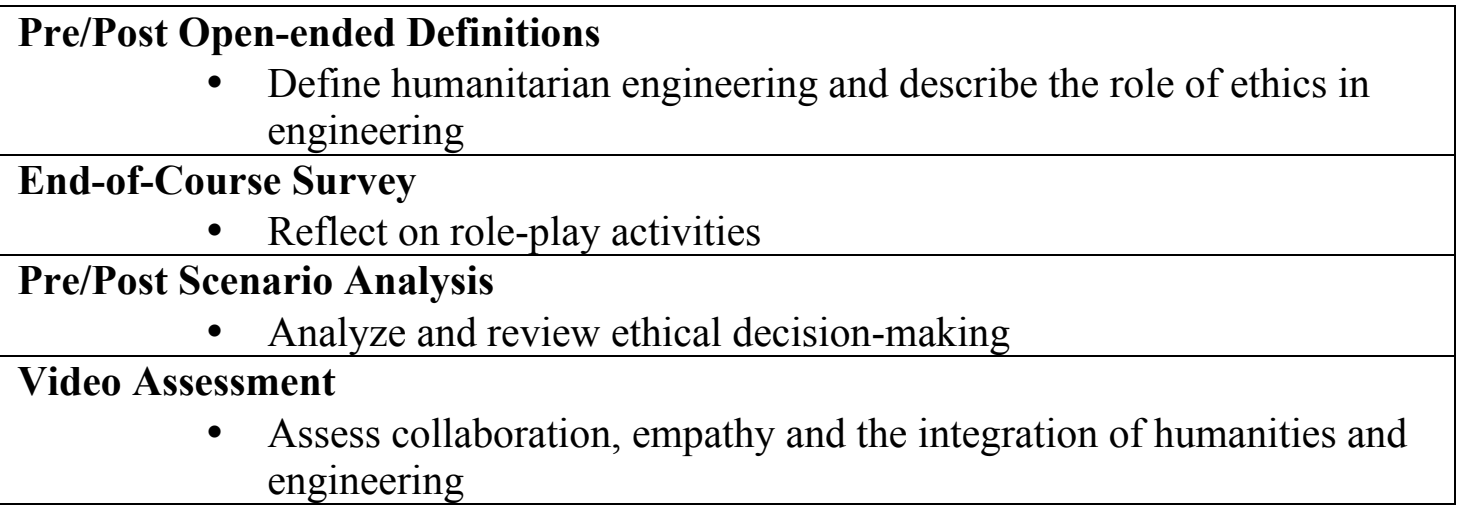

\section{Assessment 1. Pre/Post Open-ended Definitions}

At the beginning and end of the term, students were asked to define humanitarian engineering and describe the role of ethics in engineering. In most cases the pre-course responses were general and superficial: post-course responses showed more depth and specificity. A typical example from one student is shown below. The student's written responses are italicized.

Prompt Question: Define humanitarian engineering:

Pre-course response: It means to include art and humanities.

Post-course response: To me humanitarian engineering is the ability of combining diverse fields such as religion, economy, politics, and cultures to engineering. To be a humanitarian engineer you must be able to do more than science and math, because successful projects mean more than that.

Prompt Question: Describe the role of ethics in engineering:

Pre-course response: An engineer without ethics is no engineer. You need to know how to use/apply ethics in your work. Otherwise your work is not completely done.

Post-course response: A humanitarian engineer has to be able to combine diverse fields, but also diverse point [s] of view and opinions. To do this you have to have ethics.

Without ethics a project might be mathematically and scientifically perfect but it will not work for the group of people.

Considering stakeholders:

In the post-course edition of Assessment 1 applied at the end of the first term, we added two additional prompts in order to gather information on issues related to stakeholders. We asked "what effect did this course have on you with regard to your understanding of how multiple stakeholders might be involved in any given problem and solution?" and 
"putting yourself in the role of someone who is helping to solve an engineering problem, how do you feel about working with multiple stakeholders?"

In general, student responses indicated that course activities gave them a broader perspective and a greater appreciation for how multiple parties and agendas are important parts of engineering problem solving. They also expressed concern, frustration, and stress about working with multiple stakeholders but confidence that the course provided tools and experience to allow them to function effectively with multiple stakeholders.

Below are relevant quotes. Each statement is from a different student.

This honestly opened my mind. It is something that I will take with me when this course ends. I feel like now when I hear about a problem I want to break it down by who is involved and affected. Working with multiple stakeholders is such a pain. Sometimes you have to accept that you can't please everyone.

Working with multiple stakeholders, multiple points of view helps you see the problem from different angles and find the best solution.

This course was very helpful in putting us into situations that led to real situations about the topic. I learn best by doing, and by being put into these kinds of situations, it really helped me learn how to approach similar circumstances in the future and what to think about. Working with multiple stakeholders is very stressful, as one has to decide carefully what they should prioritize.

This course has taught me that within a team different opinions always exist and sometimes it is better to work with agreement than argument. It is hard to balance every group's interests and needs but it helps prepare me for problem solving.

\section{Assessment 2. End-of-Course Survey}

We also employed an end-of-course survey at the conclusion of the first term that prompted students to reflect on their own evaluation of the role-play activities. There were six prompts with a Likert response scale from 1-5, where $1=$ not at all, $3=$ somewhat, and $5=$ very much. For example:

Prompt question:

How effectively did the role-play activities help you learn the material compared to traditional lecture and reading?

Average response rating $=3.6$.

$56 \%$ of the students gave a rating of 4 or 5 .

Prompt question:

How effectively did the role-play activities help you understand the combined value of engineering and humanism?

Average response rating $=3.8$.

$67 \%$ gave a rating of 4 or 5 . 
We obtained similar results regarding student engagement in the material, class participation, research abilities, and interest in the course. These indirect results help confirm our preliminary conclusions that role-playing is an effective educational activity, particularly in the context of an interdisciplinary course.

\section{Assessment 3. Pre/post Scenario Analysis}

Additionally, students were given a scenario involving the use of a potentially hazardous chemical used in a medical product. The pre-test, issued in the beginning of the first term of "Humanitarian Engineering Past and Present," asked them how they would respond given the issues embedded in the scenario - environmental racism, following government regulations/company policy, dealing with multiple perspectives, and possible

whistleblowing. In the post-test, which was delivered at the end of the second term, they were asked to review and critique their pre-test responses.

Pre-test responses typically just re-stated the problem and did not provide a detailed action plan. In their post-test critique of their earlier responses, nearly all of the students integrated some course concepts as a guide to making an ethical action plan. Our preliminary conclusion is that the post-test responses showed more depth, more concern for the human aspects of the issue, and greater integration of ethical decision making. In the post-tests, some students wrote about making moral, principled decisions as being more important than allegiance to the company, which suggests a deeper understanding and concern for social justice.

\section{Assessment 4. Video Assessment}

At the end of the second term, 15 of the enrolled students volunteered to participate in a recorded session where they gathered in random teams and were asked to discuss a scenario and prepare a written response. Each team was audio and video recorded and the sessions transcribed. Our intent is to fully analyze the group dynamics, discourse, and content in a more in-depth fashion than the preliminary findings reported here. The five teams ended up same-gendered. Although this will be avoided in the future, some interesting results emerged, perhaps because of that demographic. We identify the teams as follows: F1 and F2 (all-female teams), M1, M2, and M3 (all male teams).

All student teams were given the same photograph and brief scenario. The photo was one of Dorothea Lange's less widely recognized images of Dust Bowl migrant families. The image portrayed three children in an informal encampment. The instructions asked students to determine what they could about the conditions of this family in order to recommend interventions that would improve their lives. We purposefully gave few details and left the kind and extent of intervention completely open-ended; this was to encourage students to think as broadly as they could.

Our preliminary findings indicate a strong grounding in collaboration for all teams and individuals; strong evidence of empathy among some (but not all) teams and individuals; and varying degrees of learning that integrates the humanities and engineering. We summarize our findings below. 
Collaboration: All teams and individuals appeared to be engaged. Individuals seemed to have roughly equal contributions in terms of time on task and specific contributions. All teams demonstrated appropriate teamwork. People listened to each other, responded to each other appropriately, and seemed to value the contributions of others. There was little or no domination by any single person or pair of persons, no denigrating of contributions, or other negative behaviors. We saw considerable evidence of cooperation and collaboration. All teams worked well together, seemed engaged in the task, and appeared to take the engagement seriously.

Empathy: Three of the five teams demonstrated strong empathy for the people pictured in the photo. Of these three, two teams were exclusively female and one team was exclusively male. These teams (F1, F2, and M2) discussed the emotional as well as physical needs of the people pictured. F1 and F2 discussed the possibility of sexual violence. In addition to providing food, water, and toilets, F2 discussed concern for the emotional health of the people in the photo ("they look unhappy"), and addressed whether toys, picture books, and art supplies might benefit the children. One student expressed sorrow for the children ("they look trapped"). M2 not only noticed that the children looked "skinny" but also wondered what games they like to play. As one participant put it, "it's an important developmental time in their lives. They need to . . . have their experience lightened." A fourth team, M3, expressed empathy in an indirect way: they appeared concerned with the lack of details and the weight of the responsibility to decide whether the family received assistance. One member of the team said, "Based on this grainy, black and white photo, we're gonna determine if this family gets funding or not. . It's almost kind of scary. Like, they didn't look sad enough in the photo, so we're not gonna give them funding. " Of the five teams, one (M1) focused almost exclusively on the question of housing: how to provide and pay for it and where to put it, etc. This team offered very little discussion of the people in the photo. And, in spite of our having spent some time during the course discussing safety issues for women and girls, none of the male teams mentioned the safety of this family.

Integration of humanities and engineering: The video assessment described above gave us a direct evaluation of student learning. In nearly all cases, students demonstrated the capacity to think through a problem using resources and ways of thinking drawn from both engineering and the humanities. Even M1, the team that focused almost exclusively on the physical circumstances portrayed in the image - most extensively, their lack of a permanent house - wondered about whether a loan or an outright grant might offend the pride of the people under consideration. Another group (M2) wondered about cultural hierarchies. One unexpected finding was that two of the five teams failed to mention sanitation, although that had been the focus of our course. Nevertheless, each team demonstrated some level of concern for social justice issues.

\section{Assessment Summary}

Preliminary assessment data indicate students achieved a deeper understanding of the role of ethics, empathy, and social justice when addressing a variety of engineering problems. Students are surprised and sometimes discomfited by the discovery that engineering requires more of them than deriving the single-answer solution the instructor expects. However, by the end of a course that pushed students outside their comfort zone and 
engaged them in a variety of instructional activities designed to connect humanity and technology, we have early confidence that students achieved our desired learning outcomes.

\section{Discussion and Conclusion}

Throughout history individuals have questioned whether engineering is just math and science. Even though engineering is supposed to be as objective as possible, it is not just math and science. To be an engineer you need to have knowledge of the past and knowledge about people and their relationships.

Excerpt from a student essay from

Humanitarian Engineering Past \& Present

Through this range of embodied, immersive and traditional class work, students developed a nuanced understanding of how engineering solutions are embedded in complex issues of race, class, status, immigration, gender, geography, politics, finance and other forms of power - i.e., the very issues that generate ethical tension and social strain. Through role-playing, students experienced the difficult social interactions that usually precede a large-scale engineered solution to a complex problem.

By the end of the first term, students had been exposed to ethical considerations, social complexity and basic sanitation solutions before turning their attention to contemporary sanitation problems in the developing world. In the following term, students applied their knowledge of sanitation issues and solutions in turn-of-the-century Worcester to similar problems that currently exist in marginalized communities in the United States and in too many places in the developing world.

In "Humanitarian Engineering Past and Present," contextual understanding and engineering solutions go hand in hand. Students learn engineering principles alongside of social contexts, rather than outside of their engineering education. By aligning sociocultural context with engineering content, students experience the interplay between the social, the technical, the environmental, and the financial - all aspects that complicate an engineering project, now and in the past.

They travel back in history to investigate how to mitigate the problems caused by human and industrial waste and contaminated water in the Blackstone River and Canal. Along the way, they come to understand the culture and customs of the time. Furthermore, on this journey of discovery they are exposed to the myriad tradeoffs and ethical considerations inherent in a large civil engineering project, regardless of time or place.

This experimental course is designed to introduce students to basic engineering principles. It is also designed to make them better engineers. In "Humanitarian Engineering Past and Present," students are challenged to consider how engineers contribute to the betterment of society, and they are encouraged to appreciate the role of the humanist engineers in achieving that goal. Ultimately, we seek to instill the knowledge that solutions are not merely technical. Rather, the biggest challenges are often non-technical and human-centered. 
Despite the fact that I was raised with privilege I am not blind to the social justice issues that impact our country in the modern day nor those in the past... A fundamental part of humanitarian engineering is for those who have privilege to consider those who don't have the same level of privilege.

(Student response)

\section{Acknowledgements}

We are grateful for seed funding from WPI's Morgan Center for Teaching and Learning and from the Kern Family Foundation's KEEN program. We are also grateful to Joseph Cullon, who developed the historical engineering ethics materials, and to the many WPI undergraduates who helped to develop this course and who served as Peer Learning Assistants, particularly Veronica Soto-Belloso and Valentina Zapata.

\section{References}

Boudreau, K., Robinson, L., Dodson, L., DiBiasio, D., Abel, C., Sullivan, J., Gaudette, G., Bergendahl, J., Demetry, C., Kirby, P., Wobbe, K., Cullon, J., Campbell, N., Carrier, A. (2016). Humanitarian Engineering, Past and Present: A Role-Playing First-Year Course. In Center for Engineering Ethics and Society, Infusing Ethics into the Development of Engineers: Exemplary Education Activities and Programs. National Academies Press, 9-10.

Boudreau, K. (2015). To see the world anew: learning engineering through a humanistic lens. Engineering Studies 7, Iss. 2-3.

http://www.tandfonline.com/doi/full/10.1080/19378629.2015.1062506

Byrne, S. (1873). Irish Emigration to the United States. What it has been, and what it is. The Catholic Publication Society. New York, New York.

Cassedy, J.H. (1962). "The Flamboyant Colonel Waring: An Anti-Contagionist Holds the American Stage in the Age of Pasteur and Koch," Bulletin of the History of Medicine 36, 167-176.

Christie, G. (1922). "A Proposed Code of Ethics for All Engineers," The Annals of the American Academy of Political Science and Social Science 101 (May).

Estu, C. W. (1989). A Swedish Working-Class Church: The Methodists of Quinsigamond Village, 1878-1900.

A_swedish_workingclass_church_the_methodists_of_quinsigamond_village_18 781900 copy.pdf

National Academy of Engineering. (2004). The Engineer of 2020: Visions of Engineering in the New Century. Washington, DC: The National Academies Press. 
Preservation Worcester. "By the Canal: Canal District Walking Tour." Worcester, MA. www.preservationworcester.org

Rosenzweig, R. (1983). Eight Hours for What we Will: Workers and Leisure in an Industrial City, 1870-1920. Cambridge University Press.

The Sewage of Worcester in its Relation to the Blackstone River: Hearings Before the Joint Standing Committee on Public Health, on the Matter of Restraining the City of Worcester from Polluting the Blackstone River (1882). 